\title{
Studies on Quality Evaluation of Non-Dairy Probiotic Beverage Prepared from Carrot and Tomato Juice
}

\author{
H.W. Deshpande ${ }^{1}$, A. Shaikh Uzma ${ }^{1}$, S.D. Katke ${ }^{1 *}$ and N.A. Giri ${ }^{2}$ \\ ${ }^{1}$ Department of Food Microbiology \& Safety, College of Food Technology, VNMKV, \\ Parbhani, Maharashtra, India \\ ${ }^{2}$ ICAR-Central Tuber Crops Research Institute, Trivandrum, Kerala, India \\ *Corresponding author
}

\section{A B S T R A C T}

Keywords

Carrot juice,

Tomato juice, Non

dairy probiotic

beverage,

Lactobacillus

acidophilus and

Sachharomyces

bouladii

Article Info

Accepted:

15 May 2019

Available Online:

10 June 2019
The carrot and tomato juice (70:30) with $18^{0} \mathrm{Bx}$ inoculated using $10 \%$ mixed culture of $L$. acidophilus and $S$. boulardii (1:1) and fermented for 20 hours was standardized for development of probiotic carrot and tomato beverage. Various physico-chemical attributes of the beverage like TSS, titratable acidity, $\mathrm{pH}$, total sugars, reducing sugars and non-reducing sugars. The color was found to orange red which was most acceptable for carrot and tomato based beverage. Further, viscosity of beverage was found to be decreased with increase in temperature. The microbiological analysis showed that prepared beverage contained optimum level of cultures i.e. $7.5 \times 10^{9} \mathrm{CFU} / \mathrm{mL}$ and yeast and mold $3.5 \times 10^{9} \mathrm{CFU} / \mathrm{mL}$ was free from any traces coliform bacteria. Hence, it can be concluded that the carrot and tomato juice has the potential as a carrier of probiotic culture for the preparation of carrot and tomato probiotic beverage.

\section{Introduction}

Carrot (Daucus carota L.) is the most important crop of Apiaceae family. It is a root vegetable that has worldwide distribution. Carrots were first used for medical purposes and gradually used as food. Written records in Europe indicated that carrots were cultivated prior to the tenth century. The colors of the carrot root flesh may be white, yellow, orange, red, purple, or very dark purple.
Orange carrots, today more popular, were developed in the 15 th and 16 th centuries in Central Europe. A rapid rise in the popularity of orange carrots was observed with the recognition of its high provitamin A content.

Carotenoids and anthocyanins are the major antioxidant pigments found in carrots. Carotenoids are the yellow, orange, or red colored phytochemicals found in most yellow and orange fleshed cultivars. The widely used 
orange carrot is high in $\alpha$ - and $\beta$-carotene and is a rich source of provitamin A. Yellow carrot color is due to lutein which plays an important role in prevention of macular degeneration. The red water-soluble anthocyanin pigment and the red water insoluble lycopene pigment present in the roots of some cultivars do not contribute to the provitamin A content.

Carrots have also a unique combination of three flavonoids: kaempferol, quercetin and luteolin. They are also rich in other phenols, including chlorogenic, caffeic and $\mathrm{p}$ hydroxybenzoic acids along with numerous cinnamic acid derivates. Among hydroxycinnamic acid and its derivates, chlorogenic acid represents $42.2 \%$ to $61.8 \%$ of total phenolic compounds detected in different carrot tissues.

Among 39 fruits and vegetables carrots have been ranked 10th in nutritional value. Carrot is a good source of dietary fiber and of the trace mineral molybdenum, rarely found in many vegetables. Molybdenum aids in metabolism of fats and carbohydrates and is important for absorption of iron. It is also a good source of magnesium and manganese. Magnesium is needed for bone, protein, making new cells, activating B vitamins, relaxing nerves and muscles, clotting blood, and in energy production. Insulin secretion and function also require magnesium. Potassium and magnesium in carrots help in functioning of muscle (Joao et al., 2014).

Carrot juice contains carbohydrates, dietary fiber, protein, fat, Vitamins A, C, B1, B2, B3, B6 and E. It also contains traditional antioxidants such as ascorbic acid, phytonutrient and beta-carotene (Gopalan et al., 1996).

Tomato (Solanum lycopersicum Mill.) belonging to the family Solanaceae and is the most important warm season fruit vegetable both nutritionally and economically grown throughout the world. It is one of the most important "protective foods because of its special nutritive value and its widespread production (Kavya, 2013). Over 20 million metric tons of tomatoes are produced each year on a world basis. Tomatoes contain abundant health-promoting related components such as lycopene, provitamin A, ascorbic acid, vitamin $\mathrm{E}$, folate, flavonoids and potassium. Among the processed tomatoes, juices may also be considered as health-promoting beverages (Naga et al., 2016).

Probiotic foods are defined as those that contain microorganisms which influence beneficially the consumer's health by improving their intestinal microbial balance (Fuller, 1989). A commercial probiotic product is considered as functional only if it contains $10^{7} \mathrm{CFU} / \mathrm{ml}$ at the time of consumption (Charalampopoulos et al., 2002).

Dairy is a very nutritious substrate for LAB but expanding the trend of vegan lifestyles; the issues of lactose intolerance and demand for low-fat and low-cholesterol foods have created a need for non-dairy probiotic products (Ranadheera et al., 2010).

Since, in addition to being delicious and nutritious, the carrot and tomato juice may be an excellent medium for the supplementation of existing nutraceutical components with probiotic culture.

Thus, pertaining to the above discussion, in response to the demand from increasingly health conscious consumers for nutritive value and medicinal properties of carrot and tomato therefore for developing probiotic carrot and tomato beverage all steps and protocol are given in this research. 


\section{Materials and Methods}

\section{Preparation of carrot and tomato juice}

Freshly harvested carrot and tomato fruits were procured from local market of Parbhani (Maharashtra). Carrot and Tomato juice was prepared by blanching of carrot and Tomato at $60^{\circ} \mathrm{C}$ for $20 \mathrm{~min}$. Then blend the juice in ratio of 70:30 of carrot and tomato juice. Its soluble solids was maintained to $18^{\circ} \mathrm{Bx}$ and stored at $4^{\circ} \mathrm{C}$ before use.

\section{Probiotic strains}

Probiotic isolates, Lactobacillus acidophilus and Sachharomyces bouladii were identified using phenotypic and genotypic methods in Department of Food Microbiology and Safety, College of Food Technology, VNMKV, Parbhani. Stock solution was prepared by adding sterile glycerol $\left(5^{\circ} \% \mathrm{v} / \mathrm{v}\right)$ to the activated culture. The glycerol stock culture was stored at $-2^{\circ}{ }^{\circ} \mathrm{C}$ in sterile screw cap tubes.

\section{Preparation of starter culture}

The starter culture was prepared with the help of method described by Thakur $\mathrm{M}$ and Sharma $\left(2^{\circ} 17\right)$, with slight modifications. $L$. acidophilus and $S$. boulardii was cultivated separately in the MRS broth and Potato Dextrose Broth for $24-\mathrm{h}$ at $37^{\circ} \mathrm{C}$. To obtain the biomass, $1^{\circ} \mathrm{mL}$ of the separately cultivated MRS broths $(5 \mathrm{ml})$ and Potato dextrose broth $(5 \mathrm{ml})$ were mixed in equal proportion $(1: 1)$ and centrifuged at $4^{\circ 00} \mathrm{rpm}$ for $1^{\circ}$ min. The obtained biomass was washed with sterile saline solution twice to remove the residual MRS media and Potato dextrose media. Thus, inoculum was prepared.

It was then introduced into pasteurized carrot and tomato juice blend $\left(1^{\circ \circ} \mathrm{mL}\right)$ for making it $1 \%$ concentration of probiotics. The inoculated juice was then incubated at $37^{\circ} \mathrm{C}$ for $24 \mathrm{~h}$ and was treated as starter culture for preparation of final beverage.

\section{Preparation of probiotic beverage}

Above prepared starter culture $(1 \mathrm{~mL})$ was then added to the pasteurized carrot and tomato juice blend $\left(1^{\circ} \mathrm{mL}\right)$ to obtain $1^{\circ} \%$ inoculation. It was allowed to ferment in incubator at $37^{\circ} \mathrm{C}$ for $2^{\circ} \mathrm{h}$. After incubation, the beverage was kept at refrigeration temperature for future use.

\section{Sensory analysis of probiotic beverage}

The sensory evaluation of carrot and tomato based probiotic beverage was carried out by $1^{\circ}$ semi-trained panel members comprised of postgraduate students and academic staff members of the faculty who had some previous experience in sensory evaluation. The panel members were requested in measuring the terms identifying sensory characteristics and in use of the score. Judgment were made through rating products on a 9 points Hedonic Scale with corresponding descriptive terms ranging from 9 "like extremely" to 1 "dislike extremely" with respect to different quality attributes such as colour, flavour, taste, aroma, mouthfeel and overall acceptability, as per the method recommended by Ranganna (1986).

\section{Physico-chemical analysis of probiotic beverage}

Following physico-chemical properties of fresh carrot and tomato juice were determined.

Total Soluble Solids (T.S.S.), Titratable acidity and $\mathbf{p H}$

Total soluble solids were measured immediately after extraction using hand 
refractometer (ERMA make). Titratable acidity, expressed as per cent lactic acid, was determined by titration against ${ }^{\circ} .1 \mathrm{~N} \mathrm{NaOH}$ using phenolphthalein as an end point indicator. The $\mathrm{pH}$ value was obtained by using a digital $\mathrm{pH}$ meter (ELICO LI612) after standardizing it with buffers of $\mathrm{pH} 4 .^{\circ}$ and 9. ${ }^{\circ}$ 15(Ranganna S.1991).

\section{Total sugars, reducing sugar and non-} reducing sugars

Total carbohydrate/sugars was estimated by standard procedure using phenol sulphuric acid (Nielsen S.S $2^{\circ} 1^{\circ}$ ). The amount of reducing sugar of fresh juice was calculated by Nelson - Somogyi method (Syed et al., $2^{\circ \circ} 7$ ) and non-reducing sugar was obtained by subtracting reducing sugars from total sugars.

\section{Color}

The colour of juice was determined by a Color HunterLab L*a*b* (Hunterlab ColorFlex EZ) (Weaver and Daniel, 2005). The equipment was calibrated using a white and black standard ceramic tile. The color is expressed as $\mathrm{L}^{*}, \mathrm{a}^{*}, \mathrm{~b}^{*}, \mathrm{c}^{*}$, and $\mathrm{h}^{*}$ color values. $\mathrm{L}^{*}$ defines lightness, $\mathrm{a}^{*}$ and $\mathrm{b}^{*}$ define red-greenness and blue-yellowness, respectively, and $\mathrm{c}^{*}$ defines saturation whereas hue angle $\left(h^{*}\right)$ is the attribute according to which colours have been traditionally defined as reddish, greenish, etc.

\section{Consistency (Viscosity)}

Viscosity was determined using the Brookfield viscometer DV-E at constant speed of $1^{\circ \circ} \mathrm{rpm}$ and varying temperature with a spindle no S-62 (Weaver and Daniel,

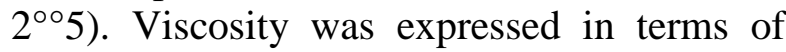
centipoises (cP). Parameters used for viscosity measurement of carrot and tomato juice were as follows:

Shear rate: $1^{\circ}$
Speed: $1^{\circ \circ} \mathrm{rpm}$

Temperature: $2^{\circ}, 25,3^{\circ}, 35$ and $4{ }^{\circ} \mathrm{C}$

\section{Microbial analysis of probiotic beverage}

The viable count of mixed culture was determined by the standard plate count method using Man-Rogosa-Sharpe agar (MRS agar) and the results were expressed as $\mathrm{CFU} / \mathrm{ml}$ juice. The yeast and mold count of beverage was determined using potato dextrose agar medium. The coli-form and basically $E$. coli are the indicator microbes of water contamination by feces. The coli-form gives red pink color colonies on the MacConkey agar. Plates were incubated at $37^{\circ} \mathrm{C}$ for 48-72 hours (Chris et al., $2^{\circ \circ} 6$ ).

\section{Results and Discussion}

\section{Sensory evaluation of probiotic beverage}

The probiotic beverage were used to sensory analyzed because the overall acceptability of the developed probiotic beverage is to be checked by different sensory evaluation panel and find out which is more delicious and tasty out of three prepared samples. In sample A there is $5^{\circ}: 5^{\circ}$, Sample B having $6^{\circ}: 4^{\circ}$ and sample $\mathrm{C}$ contains $7^{\circ}: 3^{\circ}$ of carrot and tomato juice respectively. From Table 1, it is observed that the sample $\mathrm{C}$ got more scores in color, Taste, appearance, flavor, consistency as well as overall acceptability that is 9 whereas sample A and Sample got less scores. So, from this sensory evaluation data of probiotic beverage it is showed that the $7^{\circ}: 3^{\circ}$ ratio of carrot and tomato juice was more acceptable.

\section{Physico-chemical characteristics of probiotic beverage}

The probiotic beverage was used to analyze its chemical characteristics because the nutrients present in beverage would be a 
source of food for probiotic organisms to maintain their viability in product besides quality of end product. The chemical properties of the prepared product are presented in Table 2.

From the Table 2, it is revealed that the TSS of probiotic beverage was found to $16^{\circ} \mathrm{Bx}$ as it was changed during the fermentation of beverage. The titratable acidity is a measure of shelf life of the product and guard against the attack of micro-organisms.

It also helps to ensure some chemical changes during preparation (Swientek, 1998) and storage (Langthasa, 1999).

The titratable acidity was ${ }^{\circ} .41$ percent expressed in terms of lactic acid, produced during the metabolic activity of probiotic organisms. The $\mathrm{pH}$ is inversely proportional to the acidity of any medium. The $\mathrm{pH}$ value observed was 4.455 .

The probiotic beverage contained 16.14, 15.32 and ${ }^{\circ} .82$ percent of the total sugars, reducing sugars and non-reducing sugars, respectively.

\section{Color characteristics of probiotic beverage}

In the present work, fresh carrot and tomato juice was used as substrate. This juice was very clear and didn't contain any suspend solid. Its color was orange red. After fermentation, the prepared beverage turned to light orange red color. The values of color parameters $\left(L^{*}, a^{*}, b^{*}, c^{*}\right.$ and $\left.h^{*}\right)$ for the product are depicted in Table 3.

Fig.1 Probiotic beverage samples

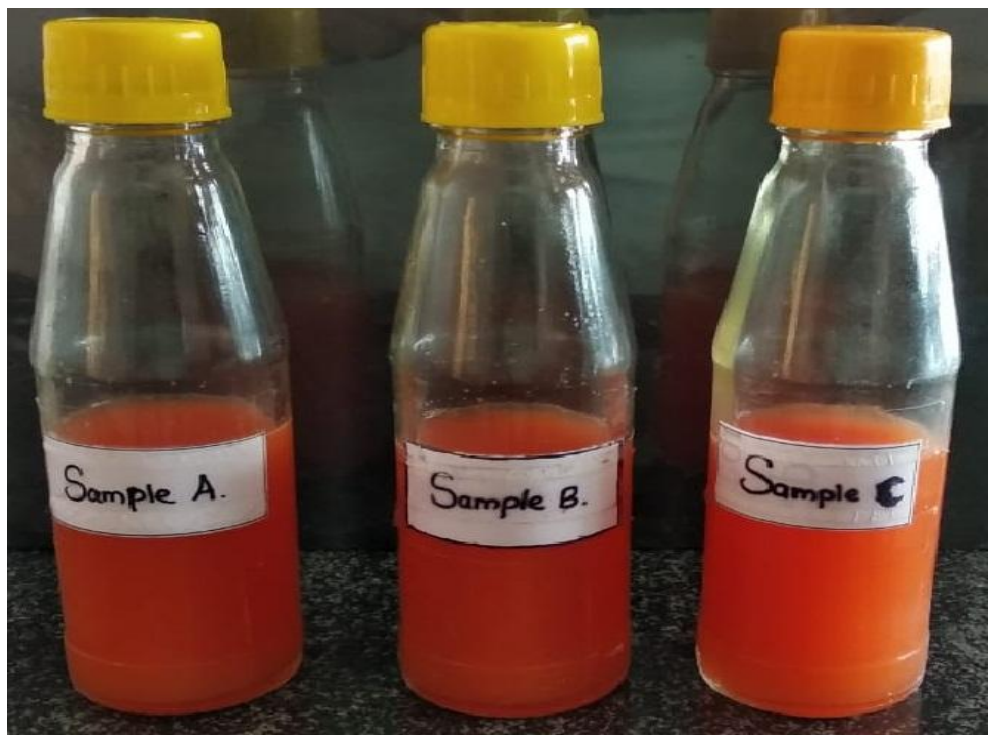

Table.1 Organoleptic characteristics of probiotic beverage

\begin{tabular}{|c|c|c|c|c|c|c|}
\hline Sample & Color & Taste & Appearance & Flavor & Consistency & Overall acceptability \\
\hline A & 9 & 7 & 8 & 7 & 8 & 8 \\
\hline B & 9 & 8 & 8 & 8 & 8 & 8 \\
\hline C & 9 & 9 & 9 & 9 & 9 & 9 \\
\hline
\end{tabular}


Table.2 Chemical characteristics of probiotic beverage

\begin{tabular}{|c|l|c|}
\hline Sr. No. & \multicolumn{1}{|c|}{ Parameter(s) } & Observations \\
\hline 1 & Total Soluble Solids (Brix) & $16 .^{\circ}$ \\
\hline 2 & Acidity (\% of lactic acid) & ${ }^{\circ} .41$ \\
\hline 3 & pH & 4.455 \\
\hline 6 & Total sugars (\%) & 16.14 \\
\hline 7 & Reducing sugars (\%) & 15.32 \\
\hline 8 & Non reducing sugars (\%) & ${ }^{\circ} .82$ \\
\hline
\end{tabular}

Table.3 Color characteristics of probiotic beverage parameters

\begin{tabular}{|l|l|l|l|l|l|}
\hline Parameters & $\mathbf{L}^{*}$ value & $\mathbf{a}^{*}$ value & $\mathbf{b}^{*}$ value & $\mathbf{c}^{*}$ value & $\mathbf{h}^{*}$ value \\
\hline Observations & 89.68 & ${ }^{\circ} .24$ & $8 . .^{\circ} 1$ & $8 .{ }^{\circ} 3$ & $88.3^{\circ}$ \\
\hline
\end{tabular}

Table.4 Effect of temperature on viscosity characteristics of probiotic beverage

\begin{tabular}{|c|c|c|}
\hline Sr. No. & Temperature $\left({ }^{\circ} \mathbf{C}\right)$ & Viscosity $(\mathbf{c P})$ \\
\hline 1 & $2^{\circ}$ & $12.6^{\circ}$ \\
\hline 2 & 25 & $1^{\circ} 4^{\circ}$ \\
\hline 3 & $3^{\circ}$ & 9.133 \\
\hline 4 & 35 & 8.267 \\
\hline 5 & $4^{\circ}$ & 7.467 \\
\hline
\end{tabular}

Table.5 Microbial analysis of probiotic beverage

\begin{tabular}{|c|l|c|}
\hline S. No. & \multicolumn{1}{|c|}{ Parameters } & Observations \\
\hline 1 & Total plate count $(\mathrm{CFU} / \mathrm{mL})$ & $7.5 \times 1^{99}$ \\
\hline 2 & Yeast and mold count $(\mathrm{CFU} / \mathrm{mL})$ & $3.5 \times 1^{0^{9}}$ \\
\hline 3 & Coli-form count $(\mathrm{MPN} / \mathrm{mL})$ & $\mathrm{ND}$ \\
\hline
\end{tabular}

From the Table 3, it is found that the luminosity of final beverage was observed to 89.68 , whereas $\mathrm{a}^{*}$ value and $\mathrm{b}^{*}$ value were .24 and $8 .{ }^{\circ} 1$, respectively. On the other hand, $\mathrm{c}^{*}$ value and $\mathrm{h}^{*}$ value of the product were observed as $8 . .^{\circ}$ and $88.3^{\circ}$, respectively. Thus based on the color values, the probiotic beverage was found be orange red in color (Fig. 1).

\section{Viscosity characteristics of probiotic carrot and tomato beverage}

The viscosity is an important characteristic to determine in food industry because it is related to the appearance and density of product. In the present investigation, the effect of temperature on the viscosity of probiotic beverage was estimated. The data related to viscosity change is tabulated in Table 4.

As shown in the above Table, the viscosity changed significantly with the increase in temperature. At temperature $2{ }^{\circ} \mathrm{C}$, the viscosity of beverage was significantly higher $\left(12.6^{\circ} \mathrm{cP}\right)$ than that observed at $4^{\circ} \mathrm{C}$ temperature $(7.467 \mathrm{cP})$. The viscosity observed at $25,3^{\circ}$ and $35^{\circ} \mathrm{C}$ were found be $1^{\circ} .4^{\circ}, 9.133$ and $8.267 \mathrm{cP}$ showing a declining 
trend as the temperature increased. The reason for viscosity reduction was that the heat causes the molecules to speed up as they bump and move around each other. Hence, more temperature means more movement of molecules and thus reducing their resistance to flow. The viscosity of tangerine and lemon juices monotonically decreases with the temperature (Magerramov et al., $2^{\circ \circ} 7$ ).

\section{Microbial analysis of probiotic carrot and tomato beverage}

The growth of undesirable organisms will spoil the product and may lead to food borne diseases affecting the healthy lives. Therefore, performing microbial analysis is mandatory in probiotic based products to assess their safety. The data related to microbiological analysis of probiotic beverage is tabulated in Table 5 .

In the present work, the count of beneficial bacteria was detected as $7.5 \times 1^{\circ 9} \mathrm{CFU} / \mathrm{mL}$ and $3.5 \times 1^{\circ 9} \mathrm{CFU} / \mathrm{mL}$ of yeast and mold beverage. This count was in range for a product to be called as probiotic (shah N.P $\left.2^{\circ \circ} 1\right)$.

On the other hand, coli-form count was also determined. And they were not detected in the sample, which showed that the product was free of any pathogenic microbes and safe for consumption.

In conclusion, the pasteurized carrot and tomato juice $\left(7^{\circ}: 3^{\circ}\right)$ was inoculated with probiotic cultures $\left(1^{\circ} \%\right)$ of L. acidophilus and $S$. boulardii (1:1) and fermented for $2^{\circ} \mathrm{hrs}$. Results showed that the chemical parameters were in sufficient amount for providing nutrition and bioactive components to consumers. Orange red color was dominating in the prepared beverage. And viscosity was also increased negligibly on the addition of probiotics in the carrot and tomato juice. Microbiological analysis found that the beverage contained the desired level of probiotic cultures $\left(1^{\circ 9} \mathrm{CFU} / \mathrm{mL}\right)$ which is helpful for maintaining the health of gastro intestinal tract. Further, the prepared beverage didn't contain any traces of coli-form bacteria, thus indicating that beverage is containing only health benefitting bacteria.

\section{References}

Charalampopoulos D., Pandiella S.S. and Webb C. ( $\left.2^{\circ \circ} 2\right)$. Application of cereals and cereal components in functional foods: A review. International Journal of Food Microbiology, 79: 131-14.

Chris B., Paul N. and Anthony P.W. ( $\left.2^{\circ \circ} 6\right)$. Food Microbiology and Laboratory Practices. Blackwell Publishing, State Avenue, USA.

Fuller R. (1989). Probiotics in man and animals. Journal of Applied Bacteriology, 66: 365-378.

Gopalan C., Ramasastry B. V. and Balasubramanian S. C. (1996). Nutritive value of Indian foods. National Institute of Nutrition. (NIN) Hyderabad, 45-47.

Joao Carlos da Silva D. $\left(2^{\circ} 14\right)$. Nutritional and health benefits of carrots and their seed extracts. Food and Nutrition Sciences, 5:2147-2156.

Joao Silva D. $\left(2^{\circ} 12\right)$. Nutritional quality and health benefits of vegetables: A Review. Food and Nutrition Sciences, 3:13541374.

Kavya S.E. (2¹3). Evaluation of Tomato Varieties for Fermented Beverage and Vinegar Production. Department of Agricultural Microbiology, University of Agricultural Sciences, Bengaluru.

Langthasa S. (1999). Processing and Preservation of Apple Pulp. Ph. D. Thesis, IARI, New Delhi.

Magerramov M.A., Abdulagatov A.I., Abdulagatov I.M. and Azizov N.D. $\left(2^{\circ \circ} 7\right)$. Viscosity of tangerine and lemon juices as a function of 
temperature and concentration. International Journal of Food Science and Technology, 42: 8०4-818.

Marja T., Seppo S. and Arthur C. $\left(2^{\circ} 13\right)$. Fermentation of Carrot Juice by Probiotics: Viability and Preservation of Adhesion. International Journal of Biotechnology for Wellness Industries, 2: $1^{\circ}-15$.

Naga S., Ramesh B., Umamahesh K. And Vijaya S. $\left(2^{\circ} 16\right)$. Probiotication of Tomato and Carrot Juices for Shelf-life. Enhancement using Microencapsulation. Journal of Food Biosciences and Technology, 6(2):1322.

Nielsen, S.S. $\left(2^{\circ} 1^{\circ}\right)$. Food Analysis Laboratory Manual (2nd Edition). Springer.

Ranadheera R.D.C.S., Baines S.K. and Adams M.C. $\left(2^{\circ} 1^{\circ}\right)$. Importance of food in probiotic efficacy. Food Research International, 43: 1-7.

Ranganna S. (1991). Handbook of Analysis and Quality Control for Fruits and
Vegetable Products (2nd Edition). Tata McGraw-Hill Publishing Company Ltd., New Delhi.

Shah N.P. $\left(2^{\circ \circ} 1\right)$. Functional foods from probiotics and prebiotics. Food Technology, 55(11): 46-53.

Swientek B. (1998). Toasts of the town. Prep. Foods, pp: 21-26

Syed H.M., Syed I., Deshpande H.W., Kulkarni K.D. and Kulkarni D.N. ( $\left.2^{\circ 0} 7\right)$. Chemical Analysis of Food Samples - Laboratory Manual. Needs Agencies, Parbhani (M.S.).

Thakur M. and Sharma R. (2०17). Development of Probiotic Pomegranate Beverage and Its Physico-Chemical and Microbial Characterization. International Journal of Pure and Applied Bioscience, 5 (1):35-41.

Weaver M.C. and Daniel R.J. (2०05). The Food Chemistry Laboratory - A Manual for Experimental Foods, Dietetics, and Food Scientists (2nd Editions). CRC Press.

\section{How to cite this article:}

Deshpande, H.W., A. Shaikh Uzma, S.D. Katke and Giri, N.A. $2^{\circ} 19$. Studies on Quality Evaluation of Non-Dairy Probiotic Beverage Prepared from Carrot and Tomato Juice. Int.J.Curr.Microbiol.App.Sci. $8\left({ }^{\circ} 6\right)$ : $1684-1691$. doi: https://doi.org/ $1^{\circ} .2^{\circ} 546 / \mathrm{ijcmas} .2^{\circ} 19.8^{\circ} 6.2^{\circ} 1$ 